\title{
Thermal generation of pentacene from soluble precursors through expulsion of carbon dioxide
}

\author{
Hsin-Hui Huang ${ }^{\mathrm{a}}$, Hsing-Hung Hsieh ${ }^{\mathrm{b}}$, Chung-Chih $\mathrm{Wu}^{\mathrm{b}, *}$, Chao-Chen Lin ${ }^{\mathrm{c}}$, Pi-Tai Chou ${ }^{\mathrm{c}, *}$, \\ Ta-Hsien Chuang ${ }^{\mathrm{d}}$, Yuh-Sheng Wen ${ }^{\mathrm{a}}$, Tahsin J. Chow ${ }^{\mathrm{a}, *}$ \\ a Institute of Chemistry, Academia Sinica, Taipei 115, Taiwan \\ ${ }^{\mathrm{b}}$ Department of Electrical Engineering and Graduate Institute of Electronics Engineering, National Taiwan University, Taipei 106, Taiwan \\ ${ }^{\mathrm{C}}$ Department of Chemistry, National Taiwan University, Taipei 106, Taiwan \\ ${ }^{\mathrm{d}}$ School of Pharmacy, China Medical University, Taichung 404, Taiwan
}

\section{A R T I C L E I N F O}

\section{Article history}

Received 10 March 2008

Revised 1 May 2008

Accepted 13 May 2008

Available online 16 May 2008

\begin{abstract}
A B S T R A C T
Highly soluble pentacene precursors possessing ketal bridges across the rings were synthesized. Pure pentacene was produced through thermal dissociation, while carbon dioxide and ethylene were extruded as volatile fragments. Thin solid film of pentacene can be prepared from these precursors by spin-coating method, followed by heating. Typical OTFT characteristics were observed from the devices prepared thereof.
\end{abstract}

(c) 2008 Elsevier Ltd. All rights reserved.
Pentacene is a p-type semiconductor with high charge mobility, and is the most promising organic gate material for OTFT devices so far. ${ }^{1,2}$ The high charge mobility is ascribed to its facile $\pi-\pi$ stacking; however, such a character also renders its low solubility in most organic solvents. ${ }^{3}$ It is rather difficult to process this material in solutions in order to prepare large films. To circumvent this obstacle, many scientists have tried to prepare soluble precursors, which are able to form films through the spin-coating method., ${ }^{4,5}$ These compounds are usually cyclo-adducts of pentacene and small volatile fragments, so that dissociation can be induced by heating to regenerate pentacene on demand. ${ }^{6}$ Carbon monoxide and carbon dioxide, by virtue of their small size and inert nature, are regarded to be ideal candidates for acting as the volatile components. ${ }^{7}$ In an earlier report, the device made of compound 1 revealed typical TFT characteristics with on/off current ratio $\sim 1.2 \times 10^{5}$ and field-effect mobility $\sim 0.01 \mathrm{~cm}^{2} \mathrm{~V}^{-1} \mathrm{~s}^{-1}$. ${ }^{8}$ However, the solubility of $\mathbf{1}$ in common organic solvents is still not quite satisfactory for practical usage. As a strategic design, it is anticipated that the more twisted backbone like compound $\mathbf{2}$ should further enhance the solubility. In this Letter, an attempt toward the synthesis of $\mathbf{2}$ was accomplished via the ketal intermediate 3. Pure

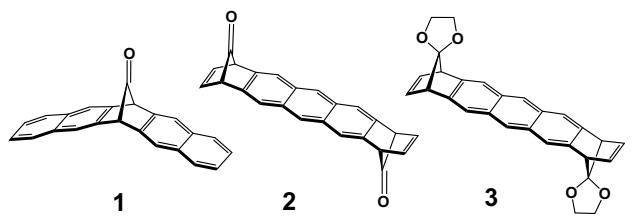

\footnotetext{
* Corresponding authors. Tel.: +886 2 27898552; fax: +886 227884179 (T.J.C.) E-mail address: tjchow@chem.sinica.edu.tw (T. J. Chow).
}

pentacene can be generated from 3 either by direct heating or via 2 through acidic hydrolysis. This is the first example showing the production of pentacene by the extrusion of $\mathrm{CO}_{2}$.

A pathway toward the synthesis of compound $\mathbf{2}$ is depicted in Scheme 1, which starts from double annulations between anthradiquinone 4 and 2,3,4,5-tetrachlorocyclopentadienone ketal 5. ${ }^{9}$ The adduct $\mathbf{6}$ may appear in six possible geometrical isomeric forms,
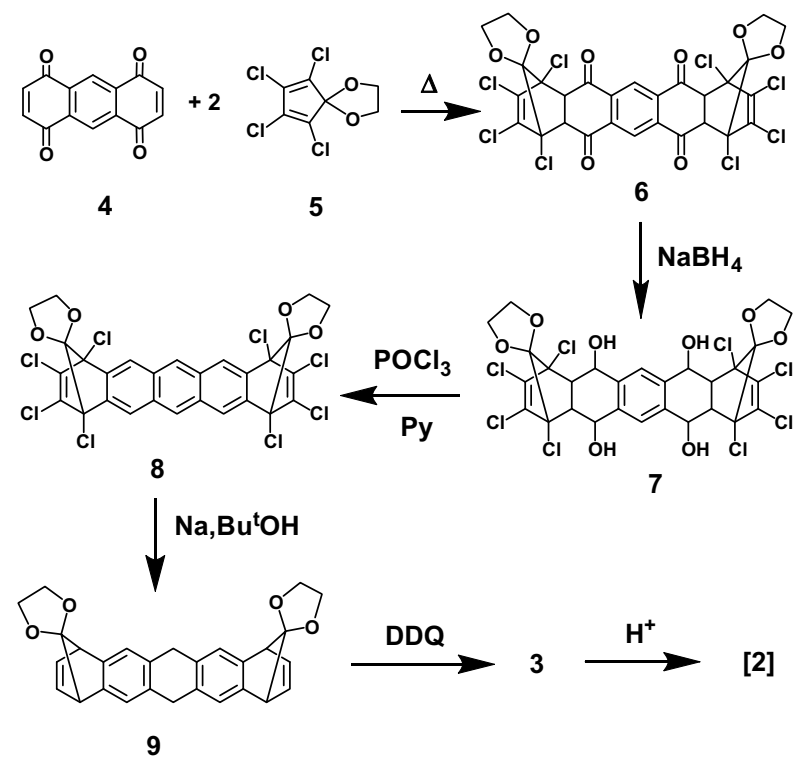

Scheme 1. The synthesis of compound $\mathbf{3}$ via 8. 
among them only the endo-anti-endo and endo-syn-endo isomers were observed as a result of the well-known endo-effect. The molar ratio of syn and anti isomers can be estimated by the corresponding aromatic ${ }^{1} \mathrm{H}$ NMR signals in the mixture, that is, singlet at $\delta 8.59$ and 8.54 , respectively, and was found to be about 3/1. Aromatization of the central anthracene moiety was accomplished by a reduction/dehydration sequence, that is, by reducing the carbonyl groups to hydroxyls in 7 with sodium borohydride, followed by dehydration with phosphoryl chloride in the presence of pyridine to yield $\mathbf{8}$. The syn and anti isomers of $\mathbf{8}$ can be separated by silica gel chromatography. ${ }^{10}$ The three aromatic ${ }^{1} \mathrm{H}$ NMR signals of anti-8 appeared at $\delta 7.91$ and 8.40 , which are very close to those of syn-8 at $\delta 7.84$ and 8.19. The overall yield of $\mathbf{8}$ (two isomers) from 4 was about $65 \%$. Compound 8 can be used for the preparation of 1,2,3,4,8,9,10,11-octachloropentacene (10), which has been predicted to be a potential n-type FET material. ${ }^{11}$ The chlorine atoms were then stripped off by a reduction of sodium in the presence of $t$-butanol. However, under such a condition the central aromatic ring was also reduced to yield compound $\mathbf{9}$. The aromaticity can be regenerated by the oxidation with dichlorodicyanoquinone (DDQ). The ${ }^{1} \mathrm{H}$ NMR spectrum of $\mathbf{3}$ is similar to that of $\mathbf{8}$, whereas the hydrogen atoms on the double bonds appear at $\delta 6.75$ for both anti and syn isomers. ${ }^{12}$ The yield of conversion from $\mathbf{8}$ to $\mathbf{3}$ was about $15 \%$.

The stereochemistry of the anti-isomer of $\mathbf{3}$ was confirmed by X-ray crystal diffraction analysis. ${ }^{13}$ The crystal was found to be triclinic in the space group $P l$ with $a=5.9680(6) \AA, b=8.6125(9) \AA$, $c=13.6272(14) \AA, \quad \alpha=76.360(2)^{\circ}, \quad \beta=84.030(2)^{\circ}, \quad \gamma=82.906(2)^{\circ}$. Solvent molecules (dichloromethane) are incorporated in the crystal packing, and therefore hinder the intermolecular $\pi-\pi$ stacking. A drawing of the crystal structure is shown in Figure 1, whereas an anti arrangement of the two ketal groups can be clearly justified. The central aromatic region is flat, and exhibits typical absorption characteristics of the anthracene moiety.

Hydrolysis of the ketal groups of $\mathbf{3}$ in an attempt to collect diketone 2 by the standard protocol under acidic conditions was not successful due to the unstable nature of $\mathbf{2}$. A spontaneous de-carbonylation of $\mathbf{2}$ happened at ambient condition and pentacene was obtained directly from $\mathbf{3}$. For example, when ketal $\mathbf{3}$ was treated with a heterogeneous mixture of ferric trichloride and silica gel in dichloromethane, pure pentacene was obtained after filtering off the solids and drying. A similar hydrolysis could also be proceeded onto octachloride $\mathbf{8}$, yielding octachloropentacene $\mathbf{1 0}$ as dark purple solids.

The transformation can be well elaborated via the absorption spectra depicted in Figure 2. A distinctive strong absorption that appeared at $240-320 \mathrm{~nm}$ is attributed to the ${ }^{1} \mathrm{~A} \rightarrow{ }^{1} \mathrm{~B}$ transition of aromatic chromophore of each pentacene derivative. The absorption maximum of compound 3 at $276 \mathrm{~nm}$ is significantly redshifted with respect to that of $\mathbf{1}$ at $244 \mathrm{~nm}$. This is because the main chromophore in $\mathbf{3}$ is anthracene, which possesses a narrower band gap than the naphthalene moiety in $\mathbf{1}$. The absorption maximum of $\mathbf{8}$ is close to that of $\mathbf{3}$, indicating a rather mild influence induced by the presence of chlorine atoms on the non-aromatic moieties. For both $\mathbf{3}$ and $\mathbf{8}$, the weak ${ }^{1} \mathrm{~A} \rightarrow{ }^{1} \mathrm{~L}_{a}$ bands at 300 $380 \mathrm{~nm}$ with vibronic progressions nearly overlap with each other. After acidic hydrolysis, the standard pentacene absorption pattern can be clearly identified by both the strong ${ }^{1} \mathrm{~B}$ band and a very characteristic ${ }^{1} \mathrm{~L}_{\mathrm{a}}$ band. The ${ }^{1} \mathrm{~B}$ band of pentacene appears at $300 \mathrm{~nm}$, and that of $\mathbf{1 0}$ at $318 \mathrm{~nm}$. The long wavelength ${ }^{1} \mathrm{~L}_{\mathrm{a}}$ band of pentacene is located at $496-576 \mathrm{~nm}$ with characteristic vibronic sub-levels. The corresponding band of octachloropentacene is at $477-595 \mathrm{~nm}$, which is slightly red shifted with respect to that of pentacene (inset in Fig. 2).

The low thermal stability of $\mathbf{2}$ rendered it unsuitable for processing at ambient temperature. In an earlier report, Mackenzie has reported the production of benzene derivatives through a thermal dissociation of the corresponding norbornadienone ketals. ${ }^{14}$ In these reactions, an alkene and a carbon dioxide were extruded via a cycloreversion process. By directly heating 3, pentacene was produced with a nearly quantitative yield. A TGA curve (Fig. 3) indicated that the dissociation started at $215^{\circ} \mathrm{C}$, while the percentage of weight loss corresponded correctly to the sum of ethylene and carbon dioxide (Scheme 2). The formation of pentacene was confirmed also by its absorption spectrum, which was identical to the authentic sample. An analogous fragmentation was also found for the octachloride derivative $\mathbf{8}$, from which octachloropentacene 10 was obtained by heating at $285^{\circ} \mathrm{C}$. Both pentacene and octachloropentacene were obtained in high purity as indicated by their TGA profiles.

The photolysis of 3 by $366 \mathrm{~nm}$ excitation in the degassed THF was also investigated. At the early irradiation period, compound 3 seemed to expel one site of fragment, forming a tetracene derivative, as supported by the observation of the tetracene relevant vibronic progressive peaks at $420-485 \mathrm{~nm}$. However, upon extending the photolysis time, the tetracene-like absorption bands gradually decreased, while no absorption spectra ascribed to pentacene was observed. The associated photoreaction seems to be complicated, and thus is not further pursued.

The solubility of $\mathbf{3}$ in most organic solvents is considerably higher than that of $\mathbf{1}$. For example, in dichloromethane, the solubility for syn and anti forms of 3 were estimated to be 77 and $10 \mathrm{mg} /$ $\mathrm{mL}$, respectively, compared to $0.7 \mathrm{mg} / \mathrm{mL}$ of 1 . An OTFT device was made by spin-coating a toluene solution of $\mathbf{3}$ on the surface

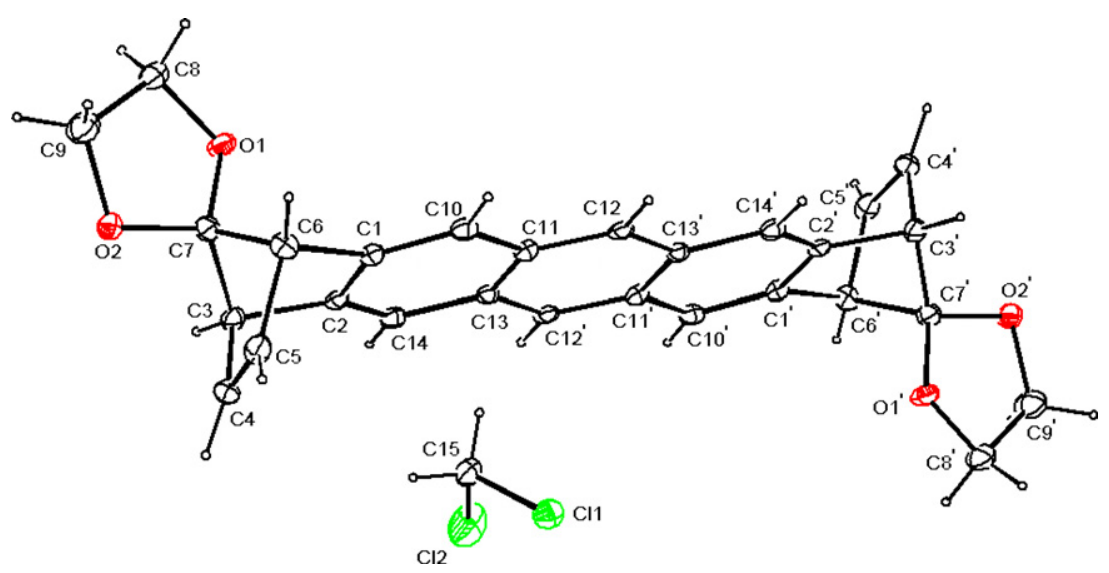

Figure 1. Crystal structure of the anti-isomer of compound 3. Numbering scheme was arbitrarily chosen. 


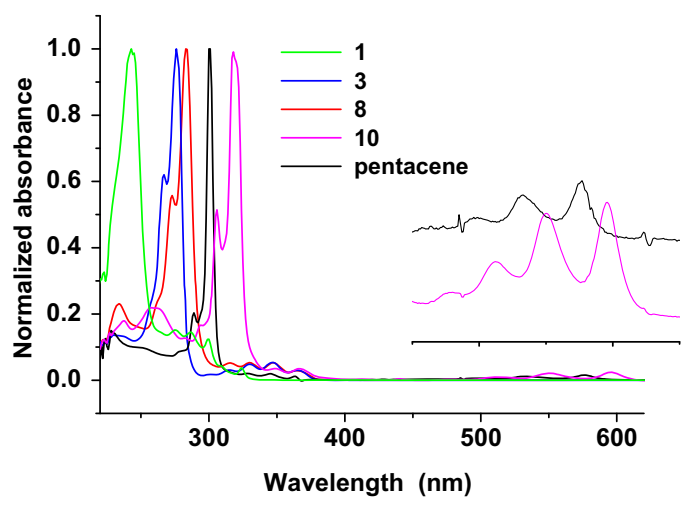

Figure 2. Normalized UV absorptions of compounds $\mathbf{1}$ (green), $\mathbf{3}$ (blue), $\mathbf{8}$ (red), 10 (pink), and pentacene (black). The pentacene and compound $\mathbf{1 0}$ were produced by acidic hydrolysis of $\mathbf{3}$ and $\mathbf{8}$, respectively. The inset shows the characteristic long wavelength absorptions of pentacene (black) and $\mathbf{1 0}$ (pink).

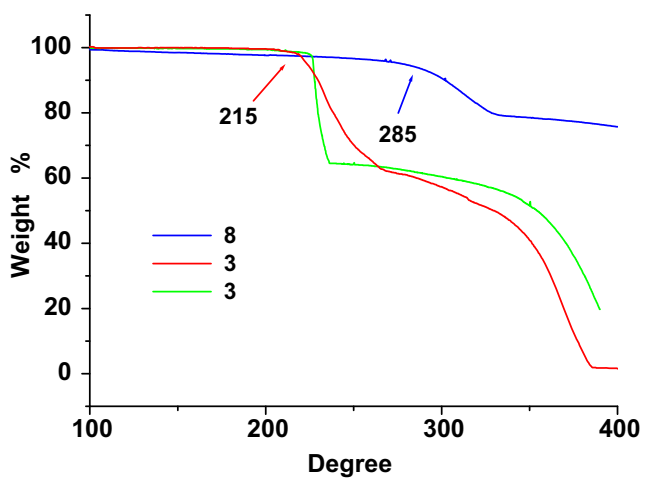

Figure 3. Thermogravimetric analysis (TGA) of compounds $\mathbf{3}$ (red) and $\mathbf{8}$ (blue) at $10^{\circ} \mathrm{C} / \mathrm{min}$ heating rate. The weight losses of $\mathbf{3}$ and $\mathbf{8}$ correspond correctly to the production of pentacene upon expulsion of $\mathrm{CO}_{2}$ and ethylene units. A better fragmentation process for $\mathbf{3}$ can be performed by slowing down the heating rate to $0.13^{\circ} \mathrm{C} / \mathrm{min}$ between 230 and $240^{\circ} \mathrm{C}$ (green) until the transformation was completed.

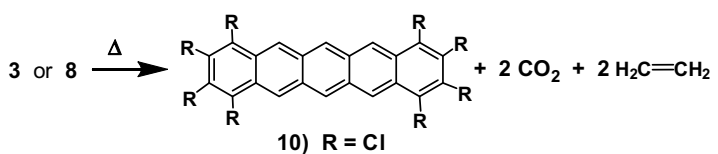

Scheme 2. The thermal dissociation of compounds $\mathbf{3}$ and $\mathbf{8}$.

of a $\mathrm{SiO}_{2}$ gate insulator. An amorphous thin film was formed after drying, and was then heated at $235^{\circ} \mathrm{C}$ for 30 min to convert 3 to pentacene. The conversion yield was high, yet the thickness of film was too thin to maintain a satisfactory quality due to fast evaporation of pentacene at the working temperature. Efforts for improving the film quality are still in progress. Nevertheless, the device made of this film did exhibit typical FET characteristics. The output parameters were measured across a source-drain channel with $1 \mathrm{~mm}$ width and $5 \mu \mathrm{m}$ length. Plot of drain current $\left(I_{\mathrm{D}}\right)$ versus drain-source voltage $\left(V_{\mathrm{DS}}\right)$ at various gate voltages $\left(V_{\mathrm{GS}}\right)$ is shown in Figure 4 (top). The corresponding transfer characteristics, that is, $\log \left(I_{\mathrm{D}}\right)$ versus $V_{\mathrm{GS}}$ for $V_{\mathrm{DS}}=-80 \mathrm{~V}$, and $\sqrt{ } I_{\mathrm{D}}$ versus $V_{\mathrm{GS}}$ in the saturation mode are also shown in Figure 4 (bottom). The OTFT exhibits an on/off current ratio about $1.7 \times 10^{3}$, and apparent field-effect mobility $(\mu)$ about $7.89 \times 10^{-6} \mathrm{~cm}^{2} \mathrm{~V}^{-1} \mathrm{~s}^{-1}$. These data evidenced the effectiveness of pentacene thus produced for use in OEFT devices.
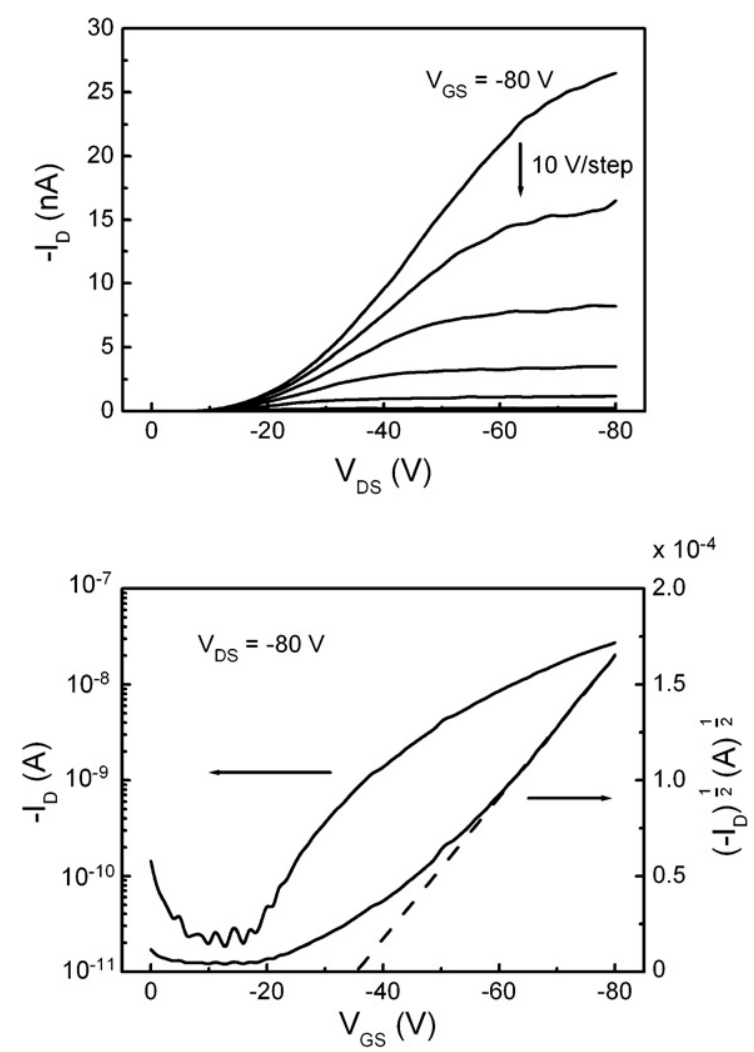

Figure 4. OTFT device performance made of 3 through spin-coating, followed by heating. Top: plot of drain current $I_{\mathrm{D}}$ versus drain-source voltage $V_{\mathrm{DS}}$ at various gate voltages $V_{\mathrm{GS}}$ obtained from an OTFT with a channel width of $1 \mathrm{~mm}$ and a channel length of $5 \mu \mathrm{m}$. Bottom: plot of $\log \left(I_{\mathrm{D}}\right)$ versus $V_{\mathrm{GS}}$ for $V_{\mathrm{DS}}=-80 \mathrm{~V}$, and $\sqrt{ } I_{\mathrm{D}}$ versus $V_{\mathrm{GS}}$ in the saturation mode. The estimated on/off current ratio is $1.7 \times 10^{3}$ and fieldeffect mobility $\mu$ is $7.89 \times 10^{-6} \mathrm{~cm}^{2} \mathrm{~V}^{-1} \mathrm{~s}^{-1}$.

In summary, a new design on the thermal production of pentacene from soluble precursors is disclosed. These compounds, in the form of ketals, can be used to produce pentacene as well as its derivatives in high purity either by heating or through acidic hydrolysis. The TGA analyses of compounds $\mathbf{3}$ and $\mathbf{8}$ indicate that fragmentations take place at 226 and $290^{\circ} \mathrm{C}$, respectively. Amorphous thin film of $\mathbf{3}$ can be prepared by spin-casting, and the thus prepared OTFT device exhibits typical FET characteristics. In future, from the synthetic point of view, it is feasible to reduce the dissociation temperature via modifying the structure on the ketal moieties of $\mathbf{3}$ and $\mathbf{8}$. This may also make photoinduced $\mathrm{CO}_{2}$ expulsion possible, avoiding thermal vaporization of pentacene and hence enhancing the quality of device. Progresses along these lines will be reported in due course.

\section{Acknowledgments}

Financial supports from the National Science Council (Taiwan) and a theme project of Academia Sinica are gratefully acknowledged.

\section{References and notes}

1. Gundlach, D. J.; Lin, Y. Y.; Jackson, T. N.; Nelson, S. F.; Schlom, D. G. IEEE Elect. Dev. Lett. 1997, $18,87$.

2. (a) Zaumseil, J.; Sirringhaus, H. Chem. Rev. 2007, 107, 1206; (b) Murphy, A. R.; Fréchet, J. M. Chem. Rev. 2007, 107, 1066.

3. Minakata, T.; Natsume, Y. Synth. Met. 2005, 153, 1.

4. Brown, A. R.; Pomp, A.; de Leeuw, D. M.; Klaassen, D. B. M.; Havinga, E. E.; Herwig, P.; Müllen, K. J. Appl. Phys. 1996, 79, 2136.

5. (a) Weidkamp, K. P.; Afzali, A.; Tromp, R. M.; Hamers, R. J. J. Am. Chem. Soc. 2004, 126, 12740; (b) Afzali, A.; Dimitrakopoulos, C. D.; Breen, T. J. Am. Chem. 
Soc. 2002, 124, 8812; (c) Afzali, A.; Kagan, C. R.; Traub, G. P. Synth. Met. 2005, $155,490$.

6. (a) Herwig, P. T.; Müllen, K. Adv. Mater. 1999, 11, 480; (b) Lai, C.-H.; Li, E. Y.; Chen, K.-Y.; Chow, T. J.; Chou, P.-T. J. Chem. Theory Comput. 2006, 2, 1078; (c) Margeti, D.; Warrener, R. N. Internet Electr. J. Mol. Des. 2005, 4, 850; (d) Okamoto, K.; Shiodera, K.; Kawamura, T.; Ogino, K. J. Phys. Org. Chem. 2008, 21, 257.

7. (a) Uno, H.; Yamashita, Y.; Kikuchi, M.; Watanabe, H.; Yamada, H.; Okujima, T.; Ogawa, T.; Ono, N. Tetrahedron Lett. 2005, 46, 1981; (b) Yamada, H.; Yamashita, Y.; Kikuchi, M.; Watanabe, H.; Okujima, T.; Ogawa, T.; Ohara, K.; Ono, N. Chem. Eur. J. 2005, 11, 6212.

8. Chen, K.-Y.; Hsieh, H.-H.; Wu, C.-C.; Hwang, J.-J.; Chow, T. J. Chem. Commun. 2007, 1065.

9. (a) Cory, R. M.; McPhail, C. L.; Dikmans, A. J. Tetrahedron Lett. 1993, 34, 7533; (b) Bénard, C. P.; Geng, Z.; Heuft, M. A.; VanCrey, K.; Fallis, A. G. J. Org. Chem. 2007, $72,7229$.

10. Selected data for anti-8: ${ }^{1} \mathrm{H}$ NMR $\left(400 \mathrm{MHz}, \mathrm{CDCl}_{3}\right) \delta 4.22-4.24(\mathrm{~m}, 4 \mathrm{H}), 4.33-$ $4.35(\mathrm{~m}, 4 \mathrm{H}), 7.91(\mathrm{~s}, 4 \mathrm{H}), 8.40(\mathrm{~s}, 2 \mathrm{H}) ;{ }^{13} \mathrm{C} \mathrm{NMR}\left(100 \mathrm{MHz}, \mathrm{CDCl}_{3}\right) \delta 67.41$ $67.99,77.31,119.93,127.66,130.25,131.12,134.58,137.63 ; \mathrm{IR}(\mathrm{KBr}) v 3549$ (w), $3472(\mathrm{~m}), 3416(\mathrm{~m}), 3234(\mathrm{w}), 2990(\mathrm{w}), 2905(\mathrm{w}), 1638(\mathrm{w}), 1616(\mathrm{w})$ $1591(\mathrm{w}), 1282(\mathrm{w}), 1241(\mathrm{~m}), 1216(\mathrm{~s}), 1166(\mathrm{w}), 1121(\mathrm{~m}) \mathrm{cm}^{-1}$. Selected data for syn-8: ${ }^{1} \mathrm{H}$ NMR $\left(400 \mathrm{MHz}, \mathrm{CDCl}_{3}\right) \delta 4.24-4.28(\mathrm{~m}, 4 \mathrm{H}), 4.35-4.39(\mathrm{~m}, 4 \mathrm{H})$, $7.84(\mathrm{~s}, 4 \mathrm{H}), 8.19(\mathrm{~s}, 2 \mathrm{H}) ;{ }^{13} \mathrm{C}$ NMR $\left(100 \mathrm{MHz}, \mathrm{CDCl}_{3}\right) \delta 67.42,68.00,77.21$, 119.93, 127.62, 130.21, 131.05, 134.57, 137.56. IR (KBr) $v 3411(\mathrm{~m}), 3060(\mathrm{w})$, 2990 (w), 2904 (m), 1662 (w), 1591 (m), $1475(w), 1336(w), 1282(w), 1218$ $(\mathrm{s}), 1166(\mathrm{~m}), 1121(\mathrm{~s}), 1030(\mathrm{~m}) \mathrm{cm}^{-1}$; MS (FAB) $\mathrm{m} / \mathrm{z} 694.85\left((\mathrm{M}+\mathrm{H})^{+}, 19 \%\right)$; Anal. Calcd for $\mathrm{C}_{28} \mathrm{H}_{14} \mathrm{O}_{4} \mathrm{Cl}_{8}$ : C, 48.18; $\mathrm{H}, 2.02$. Found: $\mathrm{C}, 48.21 ; \mathrm{H}, 2.03$.

11. Chen, H.-Y.; Chao, I. Chem. Phys. Chem. 2006, 7, 2003.

12. Selected data for anti-3: ${ }^{1} \mathrm{H}$ NMR $\left(300 \mathrm{MHz}^{\mathrm{C}} \mathrm{CDCl}_{3}\right) \delta 3.93-3.99(\mathrm{~m}, 12 \mathrm{H}), 6.75(\mathrm{t}$, $J=2 \mathrm{~Hz}, 4 \mathrm{H}), 7.73(\mathrm{~s}, 4 \mathrm{H}), 8.13(\mathrm{~s}, 2 \mathrm{H}) ;{ }^{13} \mathrm{C} \mathrm{NMR}\left(75 \mathrm{MHz}, \mathrm{CDCl}_{3}\right) \delta 55.13,64.99$, $65.53,119.71,125.76,130.71,132.76,137.92,142.25$. Selected data for syn-3: ${ }^{1} \mathrm{H}$ NMR $\left(300 \mathrm{MHz}, \mathrm{CDCl}_{3}\right) \delta 3.92-3.94(\mathrm{~m}, 8 \mathrm{H}), 3.98-4.00(\mathrm{~m}, 4 \mathrm{H}), 6.75(\mathrm{t}, J=2$ $\mathrm{Hz}, 4 \mathrm{H}), 7.72(\mathrm{~s}, 4 \mathrm{H}), 8.13(\mathrm{~s}, 2 \mathrm{H}) ;{ }^{13} \mathrm{C} \mathrm{NMR}\left(75 \mathrm{MHz}, \mathrm{CDCl}_{3}\right) \delta 55.14,65.01$, $65.58,119.73,125.75,130.73,132.78,137.97,142.28$; MS (FAB) $\mathrm{m} / z 423.16$ $\left((\mathrm{M}+\mathrm{H})^{+}, 100 \%\right)$; Anal. Calcd for $\mathrm{C}_{28} \mathrm{H}_{22} \mathrm{O}_{4}: \mathrm{C}, 78.85 ; \mathrm{H}, 6.14$. Found: $\mathrm{C}, 79.22 ; \mathrm{H}$ 5.70 .

13. Crystallographic data (excluding structure factors) for the structure of compound 3 have been deposited with the Cambridge Crystallographic Data Centre as supplementary publication no. CCDC 686515. Copies of the data can be obtained, free of charge, on application to CCDC, 12 Union Road, Cambridge CB2 1EZ, UK (fax: +44 1223336033 or e-mail: deposit@ ccdc.cam.ac.UK).

14. (a) Mackenzie, K. J. Chem. Soc. 1964, 5710; (b) Lemal, D. M.; Gosselink, E. P.; McGregor, S. D. J. Am. Chem. Soc. 1966, 88, 582. 